\title{
Relationship between the Hadley Circulation and Different Tropical Meridional SST Structures during Boreal Summer
}

\author{
JUAN FENG \\ College of Global Change and Earth System Science, Beijing Normal University, Beijing, China \\ JIANPING LI \\ College of Global Change and Earth System Science, Beijing Normal University, Beijing, and Laboratory for \\ Regional Oceanography and Numerical Modeling, Qingdao National Laboratory for Marine Science \\ and Technology, Qingdao, China \\ FEIFEI JIN AND SEN ZHAO \\ School of Ocean and Earth Science and Technology, University of Hawai'i at Mānoa, Honolulu, Hawaii \\ JIANLEI ZHU \\ China-ASEAN Environmental Cooperation Center, Beijing, China
}

(Manuscript received 20 February 2018, in final form 29 April 2018)

\begin{abstract}
The relationship of the Hadley circulation (HC) to different tropical sea surface temperature (SST) meridional structures during boreal summer is investigated over the period of 1979-2016. After decomposing the variations of the HC into the equatorially asymmetric HC (HEA), zonal-mean equatorially asymmetric SST (SEA), equatorially symmetric HC (HES), and equatorially symmetric SST (SES) components, the ratio of the HEA associated with SEA with respect to the HES associated with SES is around 2 across multiple reanalyses, which is a smaller ratio than in the annual and seasonal cycle. The reduced ratio of the HC to SST is due to the regional SST variation in the Asian summer monsoon (ASM) domain. The first leading mode (EOF1) of the regional SST variability in the ASM domain is dominated by a homogeneous warming pattern. This pattern is associated with an equatorially asymmetric $\mathrm{HC}$, but it has an opposite direction to the climatological HEA and so weakens the HEA. The second dominant mode has an El Niño-like pattern, which resembles the distribution of the principal mode of the SST in the non-ASM region. Both modes are responsible for the variation of HES. However, the SST EOF1 in the ASM domain displays a significant upward trend, favoring a suppressed HEA, and leading to the smaller ratio of the HC to SST during boreal summer. Moreover, the variation of the SST EOF1 is closely linked with the intensity of the ASM, highlighting the potential modulation by the ASM of the relation between the HC and SST during boreal summer.
\end{abstract}

\section{Introduction}

The Hadley circulation (HC) is one of the largest and most important meridional circulation systems of the global climate. The HC involves equatorward mass transport by the prevailing trade winds in the lower troposphere and poleward mass transport in the upper troposphere in the horizontal. In the vertical, the HC is characterized by an ascending branch that is located around the equator during the equinox seasons and on

\footnotetext{
Corresponding author: Dr. Juan Feng, fengjuan@bnu.edu.cn
}

the equatorial edge of the summer hemisphere in the solstice seasons and two descending branches located at the edge of the tropics or the tropical-extratropical interface of both hemispheres. The HC thus bridges the tropics and extratropics, as well as the lower and upper troposphere (Oort and Rasmusson 1970). A shift in its spatial structure and long-term variability will have an important influence on the climate (e.g., Fu et al. 2006; Lu et al. 2007; Feng et al. 2013).

The HC is a thermally driven direct circulation, with variations closely linked to the underlying thermal conditions. The potential influence of sea surface 
temperature (SST) on the variation of the $\mathrm{HC}$ has been discussed extensively. For example, the interdecadal variation of boreal winter, spring, and summer $\mathrm{HC}$ is related to the continuous warming of the Indo-Pacific warm pool (e.g., Ma and Li 2008; Feng et al. 2011; Feng et al. 2013; Li and Feng 2017), and the long-term variation of boreal autumn HC is connected with the Atlantic multidecadal oscillation (Guo et al. 2016). Meanwhile, as the most significant interannual variability of the climate system, El Niño-Southern Oscillation (ENSO) plays a role in determining the interannual variation of the seasonal $\mathrm{HC}(\mathrm{Ma}$ and $\mathrm{Li}$ 2008; Lu et al. 2008; Feng and Li 2013). During the mature phase of $\mathrm{El} \mathrm{Niño,} \mathrm{the} \mathrm{global-mean} \mathrm{HC}$ is strengthened (Oort and Yienger 1996), while the HC weakens over the western Pacific and Atlantic (Wang 2005). Different impacts are observed during different phases of El Niño events during boreal summer; that is, an intensified $\mathrm{HC}$ is seen during the summers of a developing El Niño, whereas a suppressed northern $\mathrm{HC}$ is found during the summers with a decaying El Niño (Sun and Zhou 2014). Moreover, ENSO also plays a role in affecting the extent of the HC, that is, El Niño events may induce a wider $\mathrm{HC}$, and La Niña events give a narrower extent (e.g., Nguyen et al. 2013; Guo and Li 2016).

The HC is affected by both the intensity of the underlying thermal conditions and their spatial structure; that is, meridional structures of the underlying SST exhibit essential impacts on the $\mathrm{HC}$ as well. Pioneering theoretical studies demonstrated that the position of the convergence in the boundary layer depends on the meridional structure of tropical SST (e.g., Schneider and Lindzen 1977; Rind and Rossow 1984; Lindzen and Nigam 1987; Lindzen and Hou 1988). Fang and Tung (1999) reported that heating centered off the equator tends to produce a stronger meridional circulation in the winter hemisphere than is the case when the heating is equatorially symmetric. This point is further demonstrated in observations and numerical models that show an equatorially asymmetric (symmetric) meridional circulation may be expected under the impact of equatorially asymmetric (symmetric) SST anomalies (Feng et al. 2013; Feng and Li 2013). Moreover, the amplitude of the response of the meridional circulation to different SST meridional structures may vary considerably even for the same magnitude of SST perturbations, and this is seen across multiple reanalyses (Feng et al. 2016, 2017). These results emphasize how effectively the meridional SST structure modulates both the spatial distribution and intensity of the $\mathrm{HC}$, especially for the annual-mean interannual variation and seasonal cycle.

In addition, strong seasonal differences have been detected in the $\mathrm{HC}$ in both its dynamical modulated regimes and variations. For example, during the solstice seasons [i.e., boreal summer (June-August) and winter (December-February)], the winter cell of the HC adopts the angular momentum conservation region, and the summer cell of the $\mathrm{HC}$ adopts the eddy-mediated regime. However, this is not the case for those during the equinox seasons such as boreal spring (March-May) and autumn (September-December; Walker and Schneider 2006; Bordoni and Schneider 2010). The climatological spatial distribution of the $\mathrm{HC}$ is generally equatorially symmetric during the equinox seasons, but the ascending branch of the $\mathrm{HC}$ shifts to the summer hemisphere during the solstice seasons. The $\mathrm{HC}$ tends to strengthen in boreal winter and spring, although there are inconsistencies across different datasets (Kang and Lu 2012; Nguyen et al. 2013). In contrast, the expansion of the HC is most evident during boreal summer and autumn (e.g., Fu et al. 2006; Hu and Fu 2007; Lu et al. 2007, 2009; Nguyen et al. 2013). However, the seasonal characteristics of the relationship of the $\mathrm{HC}$ to different SST meridional structures are still unclear.

Boreal summer [June-August (JJA)] is the season when the Asian summer monsoon (ASM) prevails. This is Earth's most pronounced monsoon system with strong air-sea interactions in the monsoon domain. The strong interannual variation of the ASM has significant impacts on the HC (Sun and Zhou 2014). It is illustrated that the meridional structure and seasonal evolution of the solstitial cell are related to the monsoons in Dima and Wallace (2003), however, with a focus on the seasonal cycle and global mean. The potential role of the ASM on the variation of the seasonal $\mathrm{HC}$ is still unknown. Therefore, is the relationship of the $\mathrm{HC}$ to different meridional SST structures altered during this monsoon season? If it is, what is the relation between the $\mathrm{HC}$ and SST during the monsoon season? Meanwhile, El Niño events may be in decaying or developing phases in boreal summer, suggesting that the impact of El Niño events should not be ignored in this season. What then is the potential impact of El Niño events on the relationship of the HC to different SST meridional structures during this season?

The above consideration provides the main motivation of the present study. By linearly dividing the variations of the HC and SST into two components, that is, the equatorially asymmetric and symmetric variation, the relationship of the HC to different SST meridional structures during boreal summer is explored and the possible cause is discussed. The remainder of this paper is organized as follows: Section 2 describes the datasets and methodology. Section 3 shows the relationship between the HC and different SST meridional structures during boreal summer on the global mean. The regional 
characteristics of the HC and tropical SST are demonstrated in section 4 . The possible mechanism for the observed relationship of the HC and SST during boreal summer is discussed in section 5. Finally, section 6 contains a short discussion and our conclusions.

\section{Datasets and methodology}

\section{a. Datasets}

Two atmospheric reanalysis datasets were employed to depict the features of the boreal summer (i.e., JJA) HC. These datasets were from the Japanese 55-year Reanalysis (JRA) on a horizontal resolution of $1.25^{\circ} \times$ $1.25^{\circ}$ with 32 vertical levels (Kobayashi et al. 2015), and the European Centre for Medium-Range Weather Forecasts (ECMWF) interim reanalysis (ERA-Interim, hereafter ERAI) globally archived dataset on a $1.5^{\circ} \times$ $1.5^{\circ}$ horizontal resolution with 32 vertical levels (Dee et al. 2011). Two global SST datasets are used to examine the tropical SST features. They are the Extended Reconstructed SST, version 3 (ERSST), on a $2^{\circ} \times 2^{\circ}$ resolution (Smith et al. 2008), and the Hadley Centre Sea Ice and Sea Surface Temperature dataset (HadISST) on a $1^{\circ} \times 1^{\circ}$ horizontal resolution (Rayner et al. 2003). Considering that the ASM shows strong interdecadal variation, and the intensity of the ASM has important influences on the SST over the tropical Indian and western Pacific (Wang et al. 2001; Ding and Chan 2005), the period of 1979-2016 is focused on in this study. This period corresponds to a weak ASM in general, and multiple atmospheric reanalyses are available. Moreover, the ECMWF twentieth century reanalysis (ERA-20C) from 1948 to 2010 (Poli et al. 2016) on a resolution of $2.5^{\circ} \times 2.5^{\circ}$ is used to highlight the possible interdecadal modulation on the relationship between the HC and SST. The National Centers for Environmental Prediction-National Center for Atmospheric Research (NCEP-NCAR) reanalysis is not employed because it shows limitations in depicting the variation of the HC as reported (Waliser et al. 1999; Feng et al. 2017).

\section{b. Method}

The global HC is characterized by the mass streamfunction (MSF). It is obtained by vertically integrating meridional wind and is defined by

$$
\psi=\int \frac{2 \pi R \cos \phi}{g}[\bar{v}] d p,
$$

where $v$ is the meridional wind, $P$ is the pressure, $R$ is the mean radius of Earth, $\phi$ is the latitude, and $g$ is the gravitational acceleration. The overbar and square brackets represent temporal and zonal averaging, respectively. A detailed calculation of the MSF is seen in Feng et al. (2016). According to Zhang and Wang (2013), the regional $\mathrm{HC}$ is obtained by using the irrotational component of the meridional wind averaged over a specific domain and is defined as

$$
\psi=\int \frac{2 \pi R \cos \phi}{g}\left[\bar{v}_{\chi}\right] d p
$$

where $v_{\chi}$ is the irrotational variation of the meridional wind. Other variables are the same as those in Eq. (1). The square brackets represent a zonal mean over a specific domain.

To compare the linkage between the boreal summer $\mathrm{HC}$ and different SST meridional structures, the variations of the MSF and zonal-mean SST are linearly decomposed into two components following Feng et al. $(2016,2017)$, that is, equatorially symmetric and asymmetric variations. The equatorially asymmetric HC (HEA) and equatorially symmetric $\mathrm{HC}$ (HES) variations of MSF are defined as follows:

$$
\begin{aligned}
& \operatorname{HEA}(y)=\frac{\operatorname{MSF}(y)+\operatorname{MSF}(-y)}{2} \quad \text { and } \\
& \operatorname{HES}(y)=\frac{\operatorname{MSF}(y)-\operatorname{MSF}(-y)}{2} .
\end{aligned}
$$

The SST equatorially asymmetric (SEA) and SST equatorially symmetric (SES) variations of zonal-mean SST are obtained as follows:

$$
\begin{aligned}
& \operatorname{SEA}(y)=\frac{\operatorname{SST}(y)-\operatorname{SST}(-y)}{2} \text { and } \\
& \operatorname{SES}(y)=\frac{\operatorname{SST}(y)+\operatorname{SST}(-y)}{2},
\end{aligned}
$$

where $y(-y)$ is the meridional location north (south) of the equator. The details regarding the decomposition are presented in Feng et al. (2017). Based on the above decomposition method, the interannual variation of seasonal HEA, HES, SEA, and SES are obtained. Then EOF analysis was employed to detect their principal modes and the principal component (PC). The response ratio of the HC to SST is defined as

$$
\text { Ratio }=\frac{\mathrm{PC} 1(\mathrm{HEA}) / \mathrm{PC} 1(\mathrm{SEA})}{\mathrm{PC} 1(\mathrm{HES}) / \mathrm{PC} 1(\mathrm{SES})},
$$

where PC1(HEA) refers to the first PC of the seasonal HEA; other variables have similar meanings. The numerator (denominator) in Eq. (5) represents the response amplitude of the HEA (HES) to SEA (SES). Thus, the ratio demonstrates the sensitivity of the $\mathrm{HC}$ to 
different SST meridional structures. The simultaneous influence of ENSO on the SST has been removed by subtracting the linear regression of the SST on the Niño-3 index. Correlation and regression are used to illustrate the relationships between the SST and HC, and linear fit is obtained by using the least squares regression. The statistical significance of the correlation and regression values was evaluated by means of a two-sided Student's $t$ test.

\section{Global-mean characteristics of the $\mathrm{HC}$ and zonal SST}

\section{a. Variations of the tropical zonal SST}

The climatological distribution of zonal-mean SST during boreal summer displays two peaks that are symmetrically positioned about the equator (Fig. 1a). However, the peak in the Northern Hemisphere (NH) is much higher than that in the Southern Hemisphere (SH). The climatological SEA decreases nearly linearly from $20^{\circ} \mathrm{N}$ to $20^{\circ} \mathrm{S}$ from positive in the $\mathrm{NH}$ to negative in the SH (Fig. 1b). The climatological SES has two peaks mirrored at the equator and positioned around $5^{\circ} \mathrm{S}$ and $5^{\circ} \mathrm{N}$ (Fig. 1c). The amplitude of the climatological SEA is larger than that of the SES. These climatological features are consistently depicted by the two reanalyses. The principal mode (EOF1) of the SEA has a spatial distribution that resembles the climatological structure, increasing from $20^{\circ} \mathrm{S}$ to $20^{\circ} \mathrm{N}$, with an explained variance around $73 \%$. The EOF1 of SES has a parabola-like pattern with the maximum located at the equator. The explained variance of this is about $84 \%$, indicating a greater concentration than that of the SEA. Although the two modes have different amplitudes in the two reanalyses, the spatial pattern and explained variance derived from the two reanalyses are equivalent. Considering that the first dominant mode accounts for a large proportion of the total explained variance, only the variation of EOF1 is discussed below for both the meridional circulation and zonal-mean SST.

\section{b. Variations of the global-mean $\mathrm{HC}$}

Figure 2 displays the climatological MSF and vertical motion, and their equatorially asymmetric and symmetric variations, as well as the corresponding EOF1 modes based on JRA and ERAI reanalyses. The two reanalyses are consistent with each other in depicting the climatological features of the HC. The climatological $\mathrm{HC}$ has an equatorially asymmetric meridional circulation. The ascending branch is located around $17^{\circ} \mathrm{N}$, and the descending branch around $30^{\circ} \mathrm{S}$ (Figs. 2a,d). The spatial distribution of the climatological HEA is similar
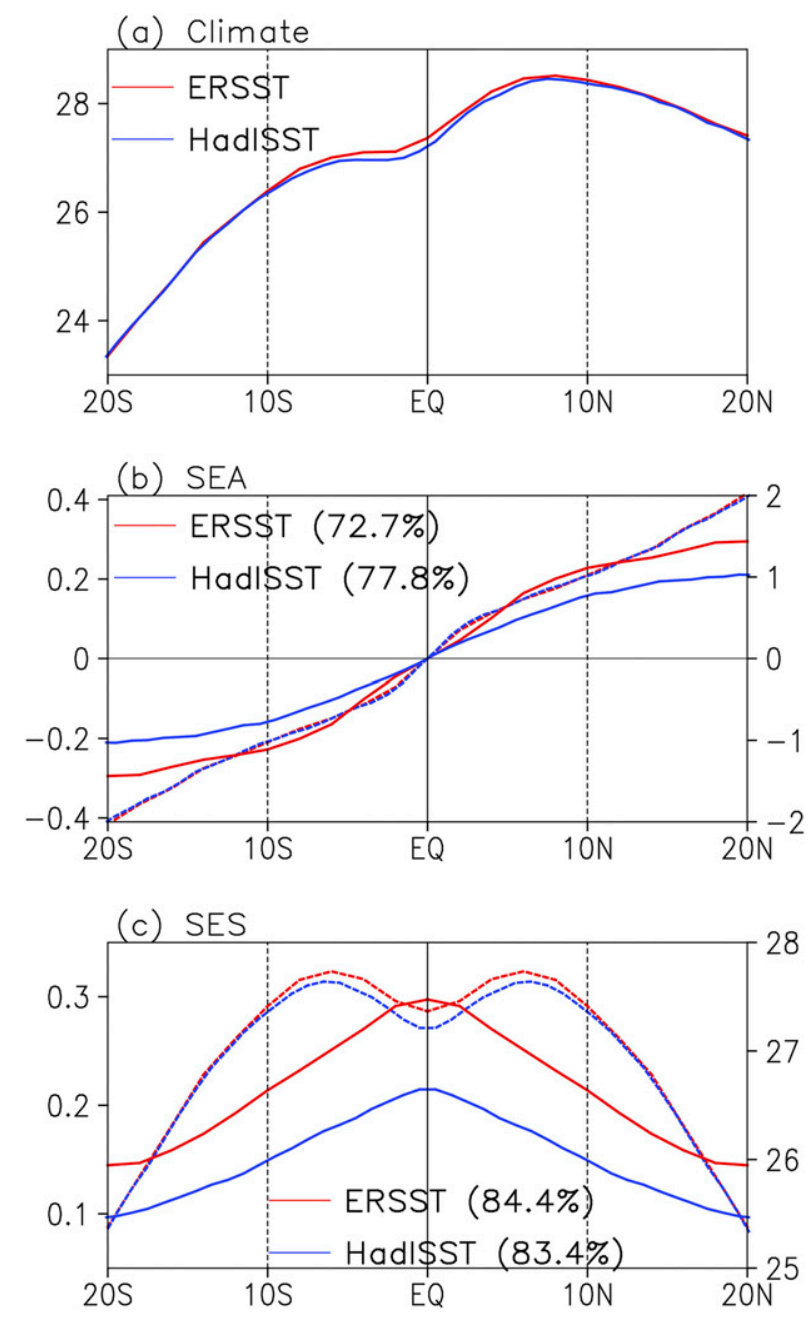

FIG. 1. (a) Climatological distribution of boreal summer zonalmean tropical SST based on ERSST (red) and HadISST (blue) $\left({ }^{\circ} \mathrm{C}\right)$. (b) As in (a), but for the distribution of the equatorially asymmetric variations (dashed line; right $y$ coordinate) and its EOF1 (solid line; left $y$ coordinate). (c) As in (b), but for the distribution of the equatorially symmetric variations.

to the original $\mathrm{HC}$, with comparable magnitude and the ascending branch in the $\mathrm{NH}$ and descending in the $\mathrm{SH}$ (Figs. 2b,e). That is, the variation of the summer $\mathrm{HC}$ is mainly dominated by the HEA, which is consistent with previous work ( $\mathrm{Li}$ and Feng 2017) and highlights the suitability of the decomposition method. The climatological HES displays an equatorial mirrored pattern, with a combined ascending branch at the equatorial edge and two descending branches around $25^{\circ}$ latitude in each hemisphere (Figs. 2c,f). Note that the magnitude of the climatological HEA is much larger than that of the HES, consistent with the larger amplitude of the SEA compared with the SES in the climatology. The EOF1 modes of HEA and HES resemble their climatological 

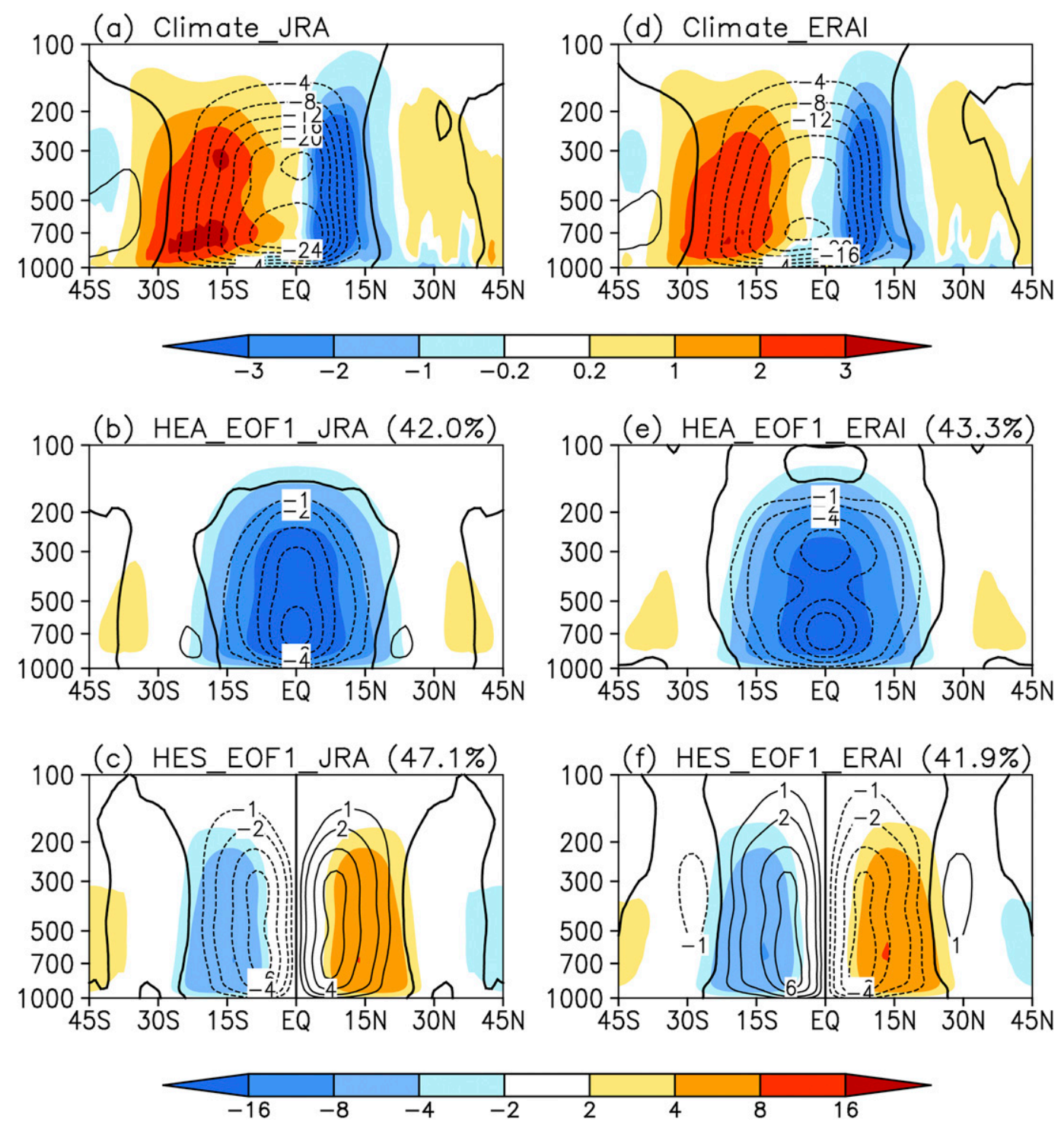

FIG. 2. (a) Climatological distribution of the boreal summer MSF (contours; $10^{8} \mathrm{~kg} \mathrm{~s}^{-1}$ ) and vertical motion (shaded; $10^{-2} \mathrm{~Pa} \mathrm{~s}^{-1}$ ) based on JRA. The solid (dotted) contours are clockwise (counterclockwise), and the zero contour is thickened. (b) As in (a), but for the climatological distribution of the equatorially asymmetric variations of the MSF (shaded) and its EOF1 (contours). (c) As in (b), but for the distribution of the equatorially symmetric variations. (d)-(f) As in (a)-(c), but based on ERAI.

distributions, accounting for more than $40 \%$ of the explained variance.

\section{c. Relationship between the HC and tropical zonal SST}

Figure 3 displays the principal components of the EOF1 (PC1) for the HC and SST. There is no evident interdecadal variation in the $\mathrm{PC} 1$ of the HEA and SEA, while the PC1s of the HES and SES show significant upward trends. The PC1s based on the two atmospheric and SST datasets are highly consistent, with correlation coefficients exceeding 0.6 across the HC and SST. Moreover, the correlation coefficients of the corresponding PC1s are 0.64 for HES against SES and 0.34 for HEA against SEA. However, there is no significant relation either between the PC1s of the HEA and SES, or of the HES and SEA. Note that the significant relationship among the PC1s of the HC and SST remains after the linear trend is removed (Table 1). These correlations confirm that the variations in HEA are associated with the SEA, and the variations in HES are related to the SES as reported in Feng et al. (2016). In addition, the 

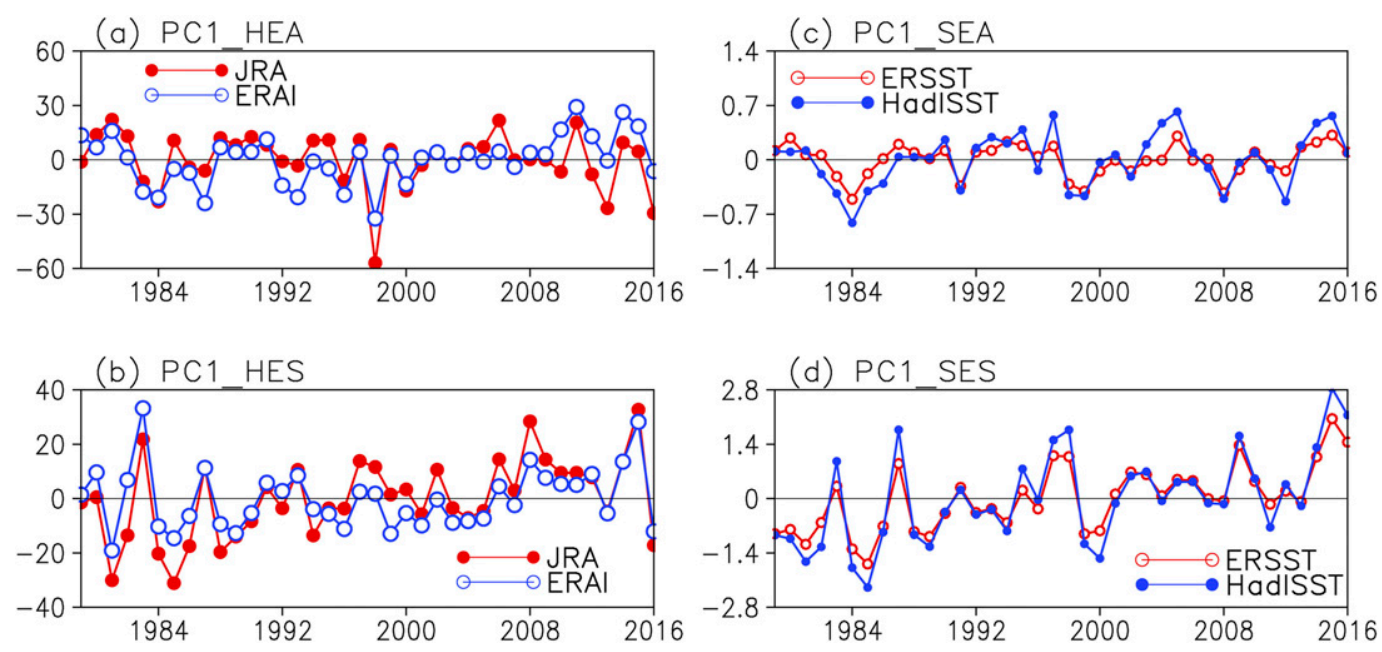

FIG. 3. (a) The PC1s of the HEA based on the JRA (red with solid circles) and ERAI (blue with open circles) reanalyses. (b) As in (a), but for the PC1s of the HES. (c)-(d) As in (a) and (b), but for the SEA and SES based on ERSST (red with open circles) and HadISST (blue with solid circles), respectively.

relationship of HEA and SEA is less significant than that of SES and HES, indicating a more complicated variation in the HEA, which will be discussed in the next section.

At this point, the corresponding amplitudes of the HEA to SEA, and of the HES to SES, are explored. Figure 4 displays scatterplots of the PC1 of the HEA against that of the SEA and of the PC1 of the HES against SES based on two SST datasets. Besides the significant linear relationship between the HEA and SEA, and between the HES and SES, it is found that the regression coefficients of HEA to SEA are larger than those of the HES to SES. A unit variation in the SEA is associated with a 24-unit variation in the HEA, whereas the corresponding variation for the HES against SES is about 12 based on JRA and ERSST (Fig. 4 and Table 1). Although the regression coefficients are different across different reanalyses, the ratio of the HEA against SEA with respect to the HES against SES is comparable among different datasets indicating that the result is robust. This result highlights that the associated amplitude of the HC to the equatorially asymmetric SST is about twice as strong as that to the equatorially symmetric SST during boreal summer. Note that the ratio of the HC to SST during boreal summer is not as large as that in the annual mean (ratio $\sim 5$; Feng et al. 2016) nor during the seasonal cycle (ratio $\sim 4$; Feng et al. 2017), suggesting that the boreal summer HC is less sensitive to the meridional SST structure. The possible causes of the reduced ratio of the HC to SST are further investigated by performing spatial correlation distributions between the PC1 of the HEA (HES) and global SST (Fig. 5). The correlation between the SST and PC1 of HEA shows approximately equatorially symmetric statistically significant negative correlations within the ASM domain. However, there are equatorially asymmetric signals in the tropical Pacific and Atlantic that are statistically significant to the south of the equator but have no counterpart to the north of the equator. This result implies that the SST within the ASM domain may deviate from the equatorially asymmetric distribution of the SST. As reported, the ASM could impact the SST in the adjacent oceans via the wind-evaporation-SST mechanism (Wang et al. 1999), and a strong ASM is associated with negative SST anomalies in the ASM domain (Wang et al. 2001; Ding and Chan 2005). Thus it

TABLE 1. Regression coefficients of the PC1 of HEA (HES) with respect to the PC1 of SEA (SES) and their ratio during boreal summer calculated using the various reanalysis datasets. The values within the parentheses (square brackets) are for the corresponding raw (detrended) correlation coefficients. Significant coefficients at the 0.05 level are marked with asterisks.

\begin{tabular}{|c|c|c|c|c|c|c|}
\hline \multirow[b]{2}{*}{ Dataset } & \multicolumn{3}{|c|}{ ERSST } & \multicolumn{3}{|c|}{ HadISST } \\
\hline & Asymmetric & Symmetric & Ratio & Asymmetric & Symmetric & Ratio \\
\hline ERAI & $15.75(0.30 *)[0.23]$ & $6.68 *(0.51 *)[0.54 *]$ & 2.4 & $11.46 *(0.29)[0.23]$ & $4.90 *(0.50 *)[0.52 *]$ & 2.3 \\
\hline JRA & $23.76^{*}(0.31 *)\left[0.33^{*}\right]$ & $11.53 *\left(0.66^{*}\right)[0.54 *]$ & 2.1 & $15.71 *(0.34 *)[0.40 *]$ & $8.01 *(0.51 *)[0.52 *]$ & 2.0 \\
\hline ERA-20C & $14.82 *(0.48 *)[0.39 *]$ & $3.58 *(0.45 *)[0.59 *]$ & 4.14 & $11.29 *(0.44 *)[0.38 *]$ & $2.96 *(0.47 *)[0.57 *]$ & 3.81 \\
\hline
\end{tabular}



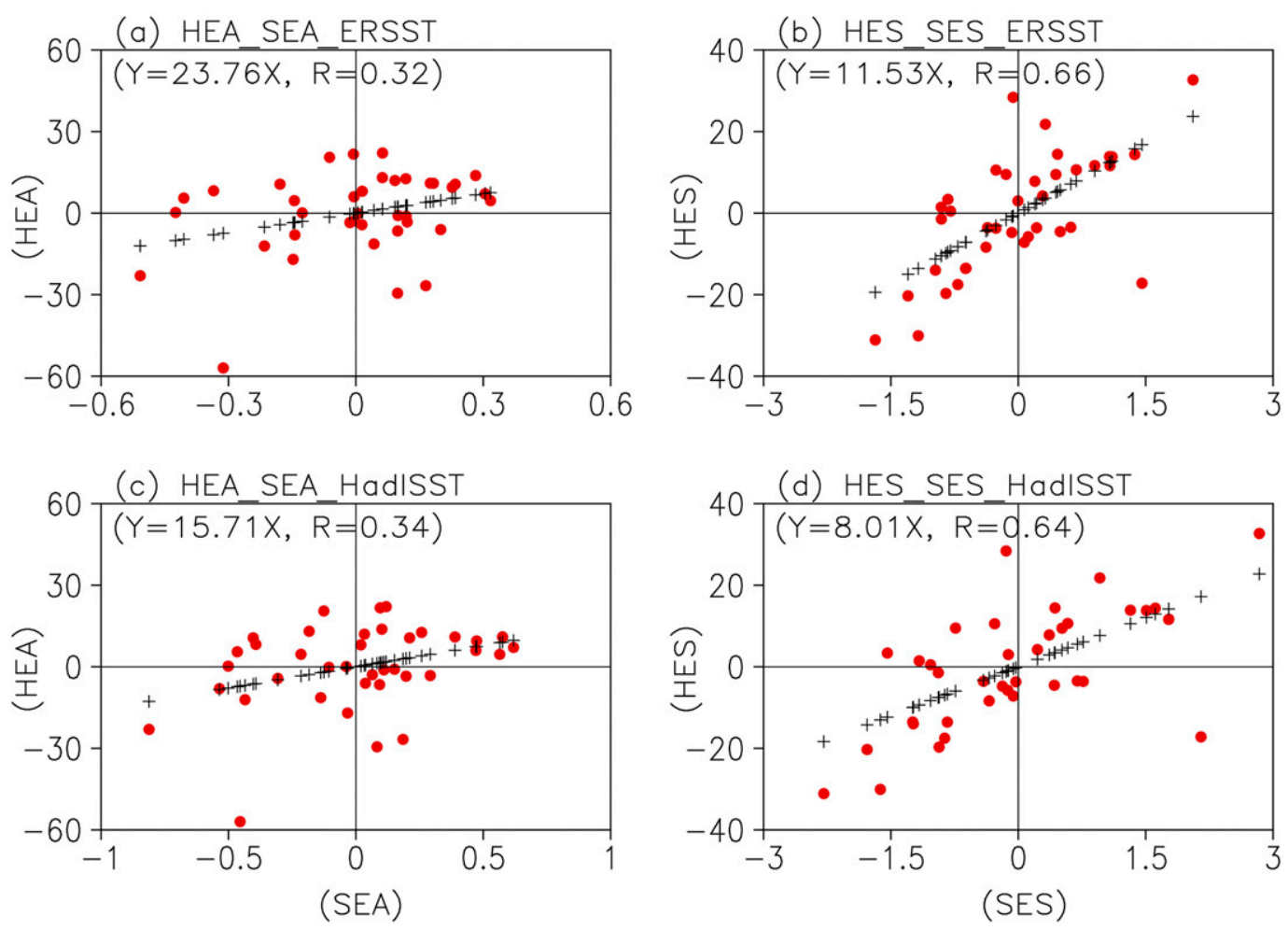

FIG. 4. (a) Scatterplot of the PC1s of the SEA against the PC1s of the HEA (red circles), and their linear fit (black crosses) based on ERSST and JRA. (b) As in (a), but for the scatterplot of the PC1s of the SES against the PC1s of the HES. (c),(d) As in (a) and (b), but based on HadISST and JRA.

is possible that the anomalous SST within the ASM domain is related to the ASM. In contrast, the correlation between the HES PC1 and SST is equatorially symmetric, with positive correlations over the tropical Indian Ocean and eastern Pacific. The distribution here is similar to the El Niño pattern. This implies that the variation of HEA leads to the reduced ratio of the $\mathrm{HC}$ to SST and suggests that the SST over the ASM domain may contribute to the reduced ratio of the HC to SST during boreal summer. To further evaluate the possible influences of the SST over the ASM domain on the relation between the $\mathrm{HC}$ and SST, we divided the global domain into two subregions, the ASM domain $\left(50^{\circ}\right.$ $\left.150^{\circ} \mathrm{E}\right)$ and non- $\mathrm{ASM}$ region $\left(150^{\circ}-50^{\circ} \mathrm{E}\right)$, to analyze the impact of regional variation on the relationship of the $\mathrm{HC}$ and SST.

\section{Regional characteristics of the $\mathrm{HC}$ and tropical zonal SST}

Figure 6 shows the climatological and zonal-mean profiles of the boreal summer SST in the ASM and nonASM regions. The zonal-mean profile of SST has an equatorially asymmetric distribution in the ASM region, increasing with increasing latitude in the $\mathrm{SH}$, but remaining unchanged in the $\mathrm{NH}$. In contrast, the zonalmean profile of SST within the non-ASM region resembles the global mean. Moreover, the SST in the $\mathrm{NH}$ within the ASM region is warmer than within the non-ASM region. In this case, we see that the regional $\mathrm{HC}$ in the two subregions shows different characteristics. For example, the ascending branch is around $20^{\circ} \mathrm{N}$ over the ASM domain, but around $10^{\circ} \mathrm{N}$ over the nonASM region (Fig. 7). Moreover, the intensity of the HC in the ASM region is much greater than in the non-ASM region. A stronger and broader HEA is seen over the ASM region than that over the non-ASM region. The spatial distribution of regional HES for the ASM region shows a monopole in one hemisphere whereas it exhibits a dipole structure for the non-ASM region. Moreover, the intensity of HES in the ASM region is much stronger than that in the non-ASM region. The distribution of the regional HC mirrors the SST distribution; that is, warmer SST favors stronger $\mathrm{HC}$.

The variability of the regional SST is investigated further to understand the linkage between the HC and SST. Only the first two dominant modes of the SST over the ASM region are statistically independent according 

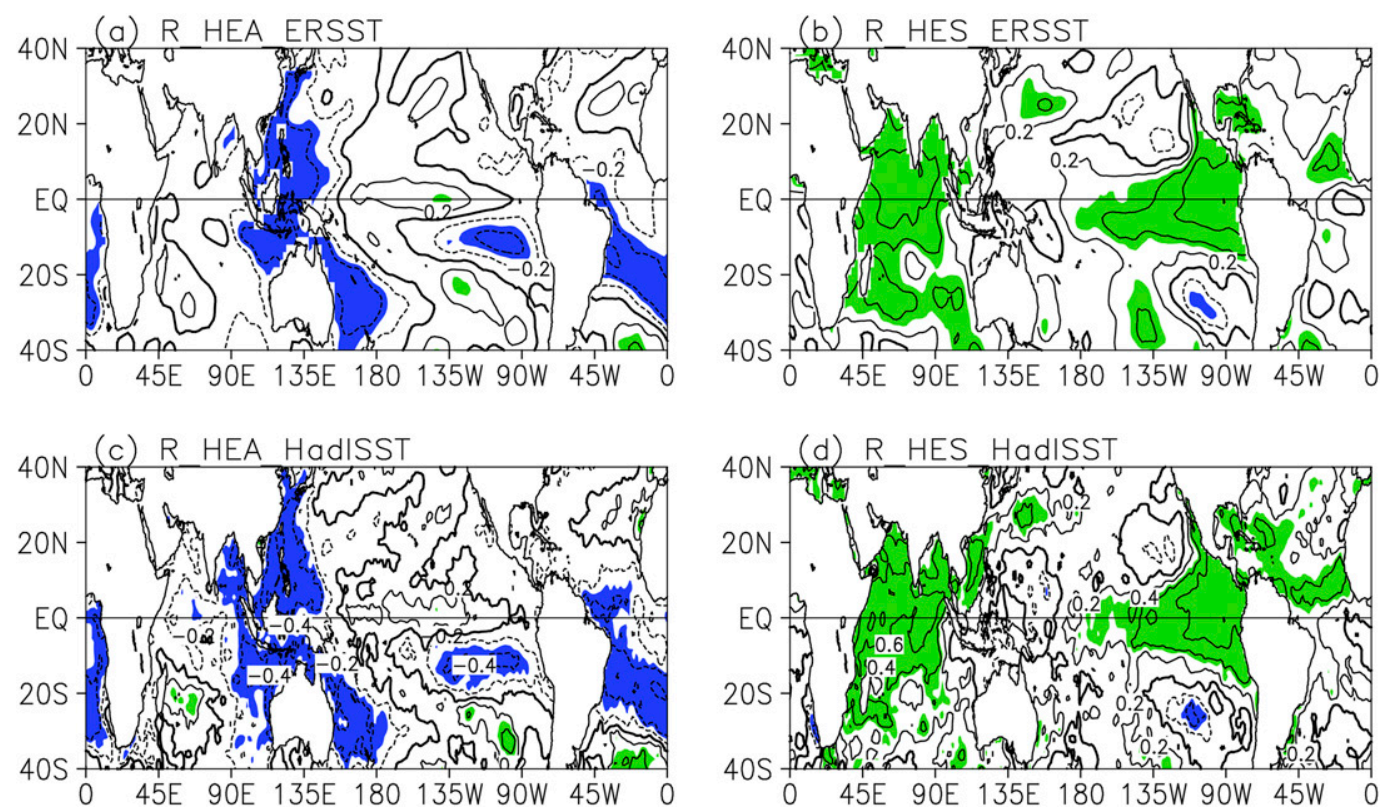

FIG. 5. (a) Correlation distribution between the HEA PC1s and SST based on ERSST. The contour interval is 0.2, and the zero contour is thickened. (b) As in (a), but for the correlations between the HES PC1s and SST. (c),(d) As in (a) and (b), but based on HadISST. Shading indicates significance at the 0.05 level.

to North's rule. The first leading mode is a homogeneous warming pattern, accounting for $45 \%(42 \%)$ of the explained variance based on ERSST (HadISST). The second mode is an east-positive-west-negative pattern, accounting for $18 \%$ (19\%) of explained variance (Fig. 8) based on ERSST (HadISST). In the non-ASM region, the first three modes could be statistically significantly separated based on HadISST, with explained variances
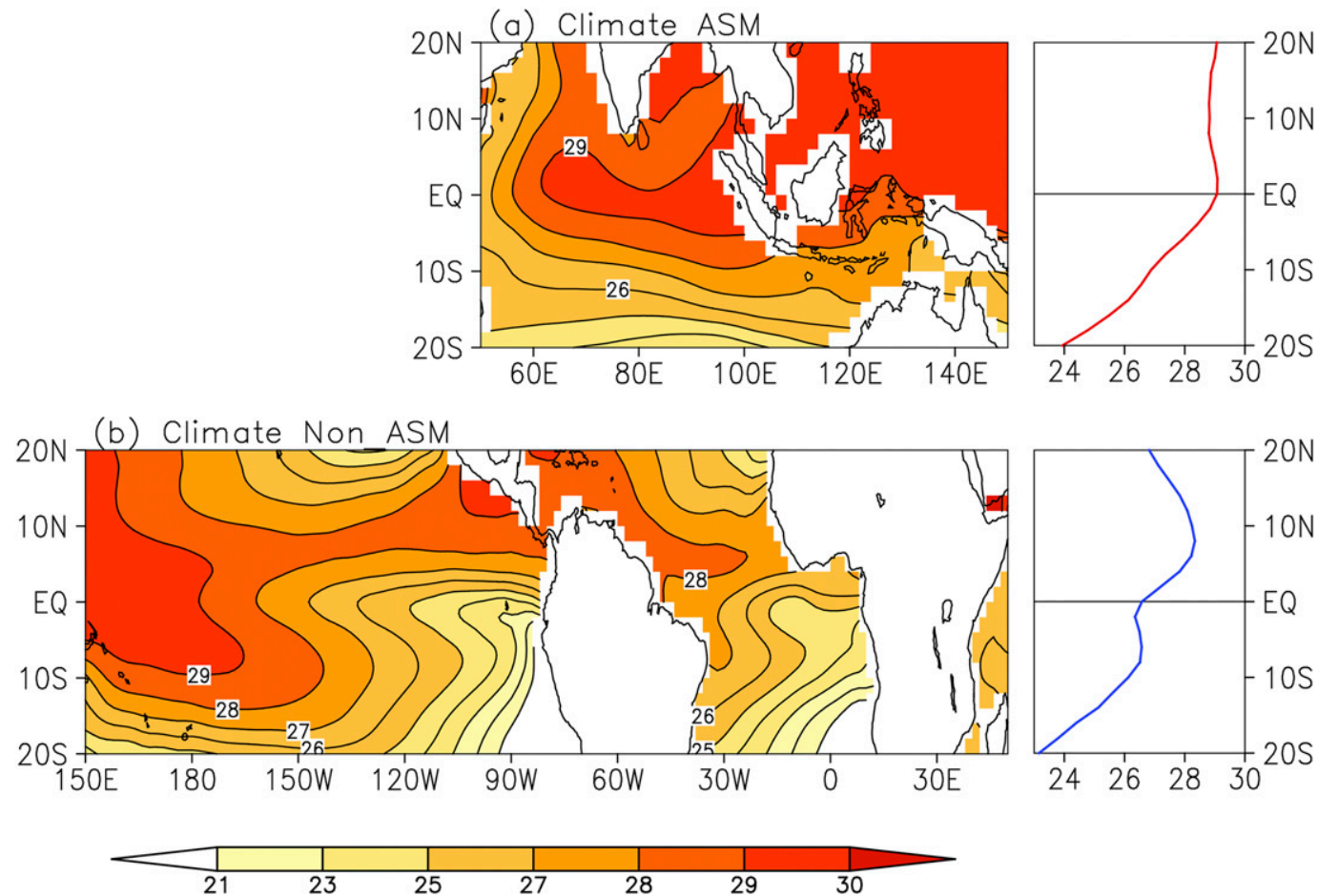

FIG. 6. The climatological mean of boreal summer SST over the (a) ASM $\left(50^{\circ}-150^{\circ} \mathrm{E}, 20^{\circ} \mathrm{S}-20^{\circ} \mathrm{N}\right)$ and (b) non-ASM $\left(150^{\circ}-50^{\circ} \mathrm{E}, 20^{\circ} \mathrm{S}-20^{\circ} \mathrm{N}\right)$ regions and their corresponding zonal-mean profiles $\left({ }^{\circ} \mathrm{C}\right)$. 

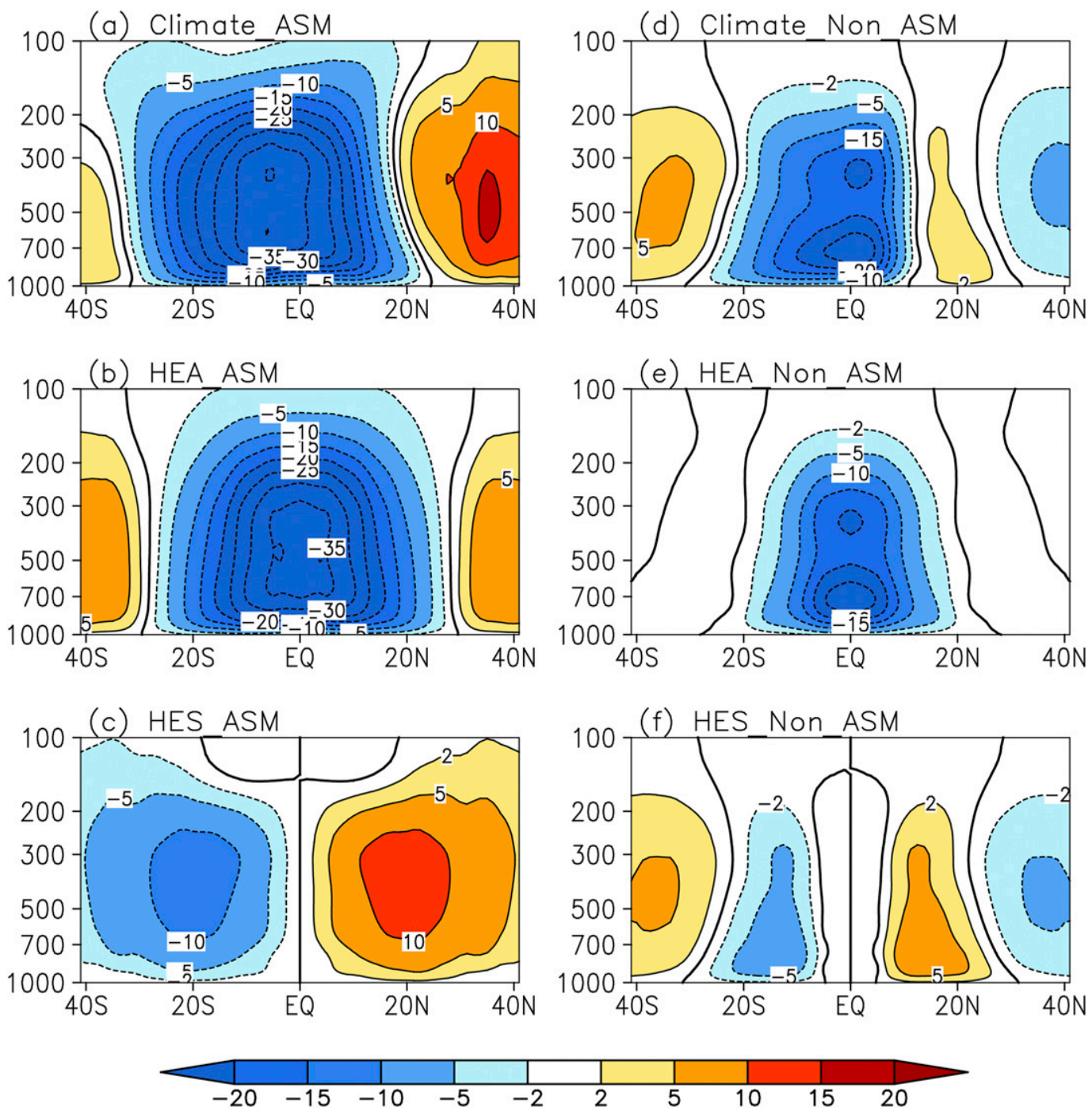

FIG. 7. (a) Climatological distribution of the HC over the ASM extent $\left(50^{\circ}-150^{\circ} \mathrm{E}\right)\left(10^{8} \mathrm{~kg} \mathrm{~s}^{-1}\right)$. (b),(c) As in (a), but for its equatorially asymmetric and symmetric variations, respectively. (d)-(f) As in (a)-(c), but over the nonASM extent $\left(150^{\circ}-50^{\circ} \mathrm{E}\right)$.

of $46 \%, 15 \%$, and $11 \%$, respectively. The second mode is similar to the named date line El Niño (Larkin and Harrison 2005), El Niño Modoki (Ashok et al. 2007), or the central Pacific El Niño (Yu and Kao 2007) pattern (figure not shown). The third mode is the named coldtongue mode ( $\mathrm{Li}$ et al. 2015, 2017). However, the second and third modes are not statistically independent according to North's rule based on ERSST. Given the disagreement between the two SST datasets on the second and third modes in the non-ASM region, only the first leading mode is illustrated (Fig. 8c). The spatial distribution of this mode resembles the classical El Niño pattern, accounting for $46 \%$ of the explained variance.
Accordingly, the dominant variability of the regional $\mathrm{HC}$ is examined. Over the ASM region, the EOF1 is characterized by an equatorially asymmetric meridional circulation, accounting for $60 \%$ of the explained variance (Fig. 9). The distribution of this mode is similar to the principal mode of the boreal summer HC (Feng et al. 2011; Sun and Zhou 2014; Li and Feng 2017), but with greater explained variance, implying that the dominant variability of boreal summer HC is mainly due to the meridional circulation over the ASM domain. In contrast, the EOF1 of the non-ASM HC is equatorially symmetric, with the combined ascending branch around the equator, and accounting for $37 \%$ of the explained variance. The structure of this mode resembles the 

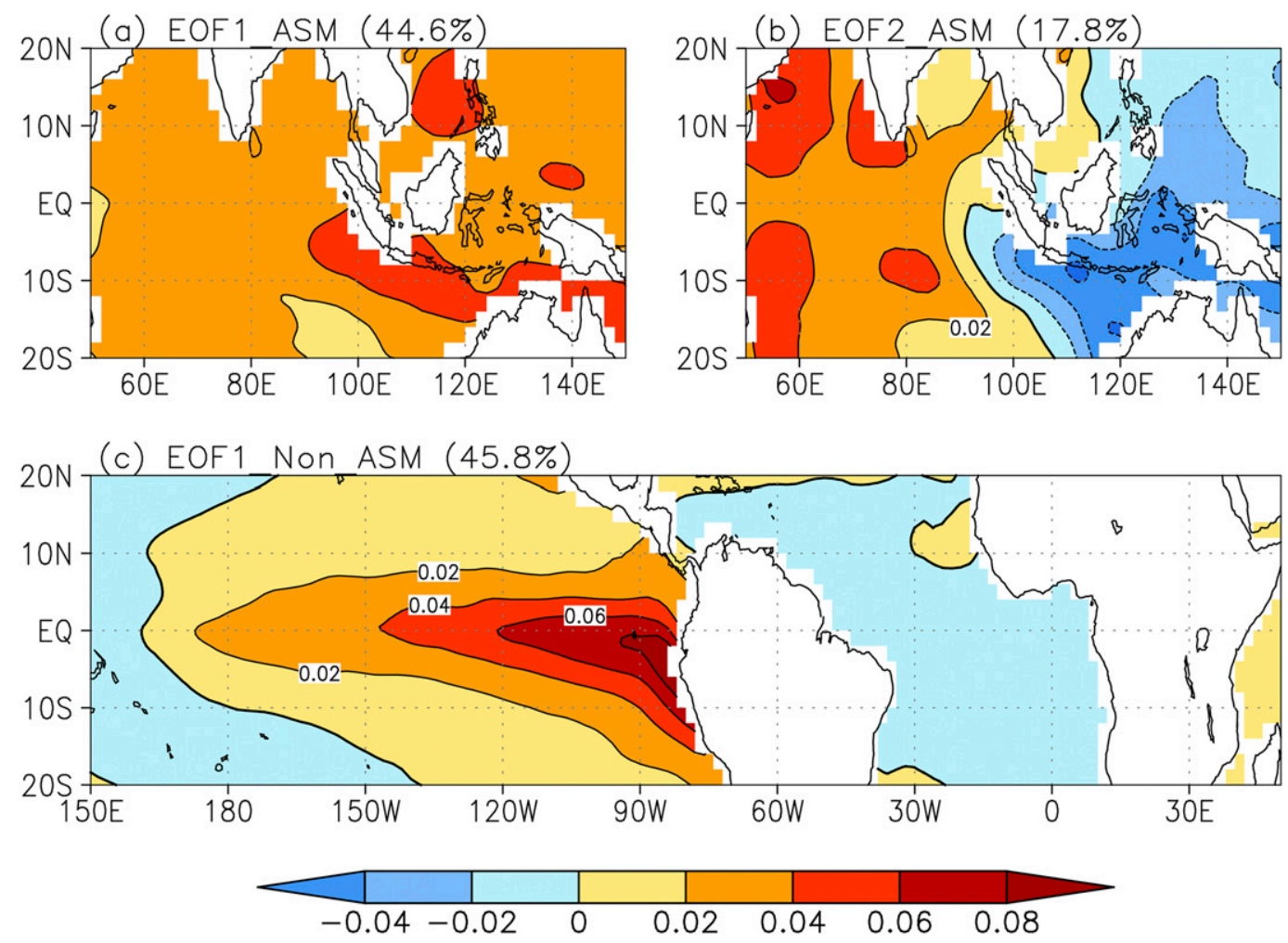

FIG. 8. Spatial distribution of the SST (a) EOF1 and (b) EOF2 of the ASM region. (c) As in (a), but for the SST $\mathrm{EOF} 1$ of the non-ASM region.

second dominant mode of the boreal summer HC (Feng et al. 2011; Sun and Zhou 2014; Li and Feng 2017). This result suggests that the variability of the $\mathrm{HC}$ in the nonASM region contributes to the second leading mode of the global HC during boreal summer. The second dominant modes for the regional HC in both the ASM and non-ASM regions display a regional equatorially asymmetric distribution with less explained variance $(<20 \%$; figures not shown) and are not discussed.

The results above demonstrate that the equatorially asymmetric variation of the boreal summer $\mathrm{HC}$ possibly comes from the regional $\mathrm{HC}$ in the ASM region, while the symmetric variation is related to the regional $\mathrm{HC}$ in the non-ASM region. This point is further verified by the statistically significant correlations between the associated PC1s. The correlation coefficient of PC1s between the global HEA (HES) and SST in the ASM (non-ASM) region is $0.39(0.57)$, which is significant at the 0.05 level, implying that the variation of HEA (HES) is related to the SST variation over the ASM (non-ASM) region (Table 1). However, the correlation of the PC1s between the global HES and SST in the non-ASM region is lower than that between the global HES and global SES as described above (i.e., 0.64) but is comparable with that between the global HEA and global SEA (i.e., 0.34).
These results imply that the SST in the non-ASM region is not the only contributor to the variation of HES but that the SST EOF1 in the ASM region is mainly responsible for the HEA during boreal summer. The possible mechanisms linking the SST in the ASM (non-ASM) region with the equatorially asymmetric (symmetric) variation of $\mathrm{HC}$ are analyzed in the next section.

\section{Possible mechanisms for the reduced response}

To detect the global SST features associated with the regional SST variations, the correlations between the SST PCs in the ASM and non-ASM regions and global SST are calculated. Significant positive correlations are seen over the ASM domain and tropical Atlantic between the SST PC1 in the ASM region and the global SST field (Fig. 10a). The significant correlations over the tropical Atlantic are mainly due to the linear trends, as they have largely disappeared in the detrended correlations. However, the correlations in the ASM domain show little change in the detrended correlations (Fig. 10b).

In contrast, an El Niño-like pattern is seen in the correlations between the SST PC2 in the ASM domain and the global SST (Fig. 10c). A similar pattern is 

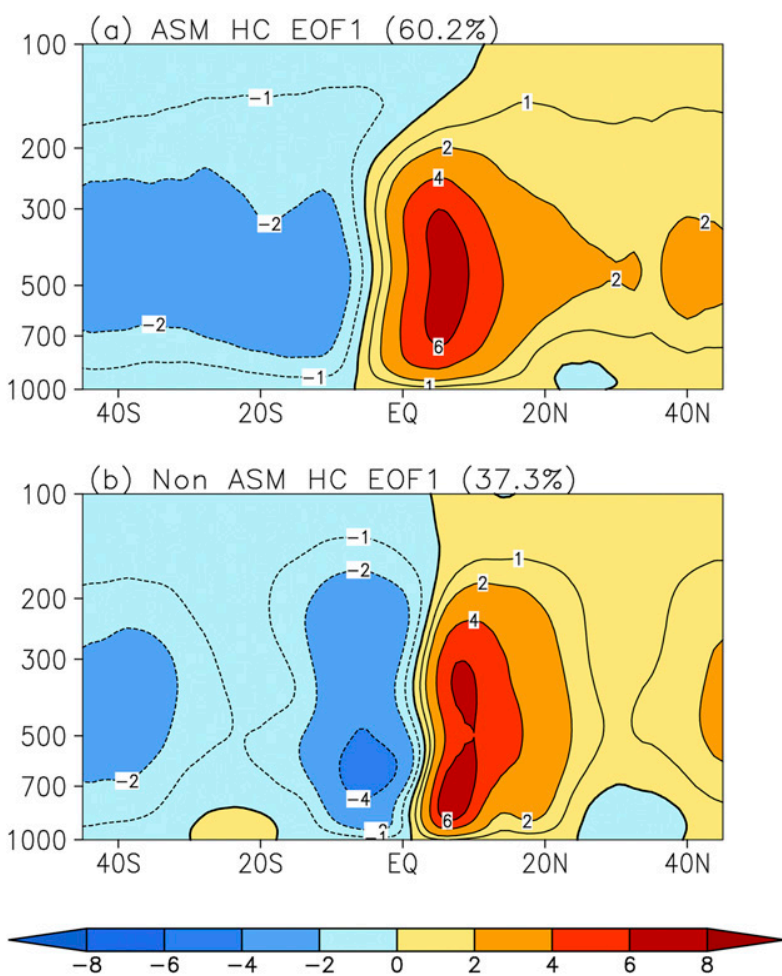

FIG. 9. (a) Spatial distribution of the regional HC EOF1 of the ASM region $\left(50^{\circ}-150^{\circ} \mathrm{E}\right)$. (b) As in (a), but for the regional $\mathrm{HC}$ $\mathrm{EOF} 1$ of the non-ASM region $\left(150^{\circ}-50^{\circ} \mathrm{E}\right)$.

observed in the correlations between the SST PC1 in the non-ASM region and global SST (Fig. 11a); that is, significant positive correlations in the eastern Pacific and Indian Oceans but negative correlations in the western Pacific. The linkage of the SST EOF2 in the ASM region to El Niño is further verified by performing an EOF analysis on the SST in the ASM region but linearly removing the influence of El Niño. It is found that the EOF2 cannot be statistically separated while the explained variance of EOF1 is enhanced (i.e., $49 \%$; figure not shown).

The above result suggests that the two SST EOF modes in the ASM region are associated with different global SST spatial distributions, implying potentially different impacts on the meridional circulation. This point is supported by the regression of the corresponding SST PCs against the global HC as shown in Fig. 12. The variation of SST PC1 in the ASM region is connected with an equatorially asymmetric meridional circulation in the global meridional circulation, ascending to the south of the equator and descending to the north of the equator, indicating that the SST EOF1 in the ASM region contributes to the variation of equatorially asymmetric meridional circulation (Fig. 12a). Note that the direction of this anomalous meridional circulation is
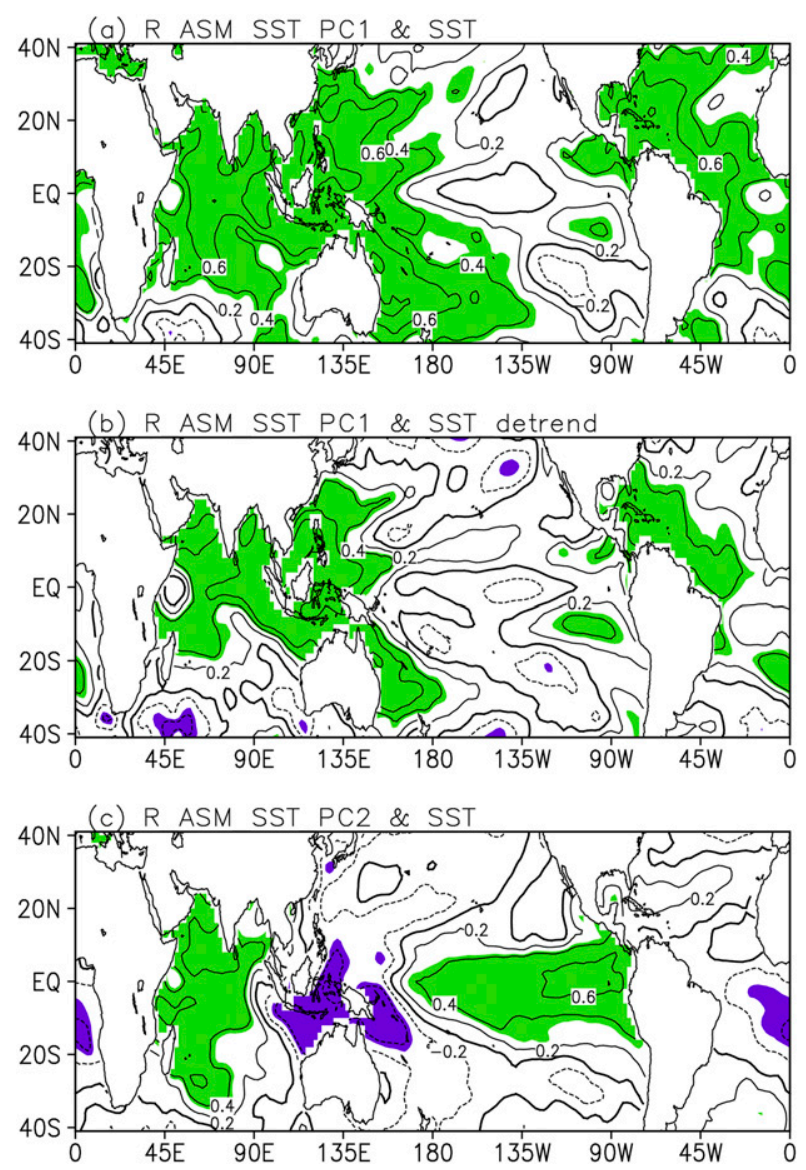

FIG. 10. (a) Correlation between the tropical SST and the SST PC1 of the ASM region. The contour interval is 0.2 , and the zero contour is thickened. (b) As in (a), but for the detrended correlations. (c) As in (a), but for the correlation with the PC2. Shading indicates significance at the 0.05 level.

opposite to the climatological distribution of the HEA, suggesting that an intensification of the SST EOF1 would oppose the climatological HEA. The SST PC1 in the ASM region exhibits a significant upward trend (Fig. 13), implying that an intensified anomalous meridional circulation would occur, and opposite to the climatological field. This anomalous circulation reduces the intensity of the climatological HEA, supporting a reduced ratio of the $\mathrm{HC}$ to SST.

Different from the variation of SST PC1 in the ASM domain, both the SST PC2 in the ASM region and the SST PC1 in the non-ASM region have an El Niño-like pattern, and the PCs are highly correlated with a correlation coefficient of 0.63 . Accordingly, these PCs generate similar meridional circulation anomalies (Figs. 12b and 11b). An equatorially symmetric meridional circulation is observed in the regression of their PCs with respect to the global MSF and vertical motion; that is, ascent around the equator but descent in the extratropics in 

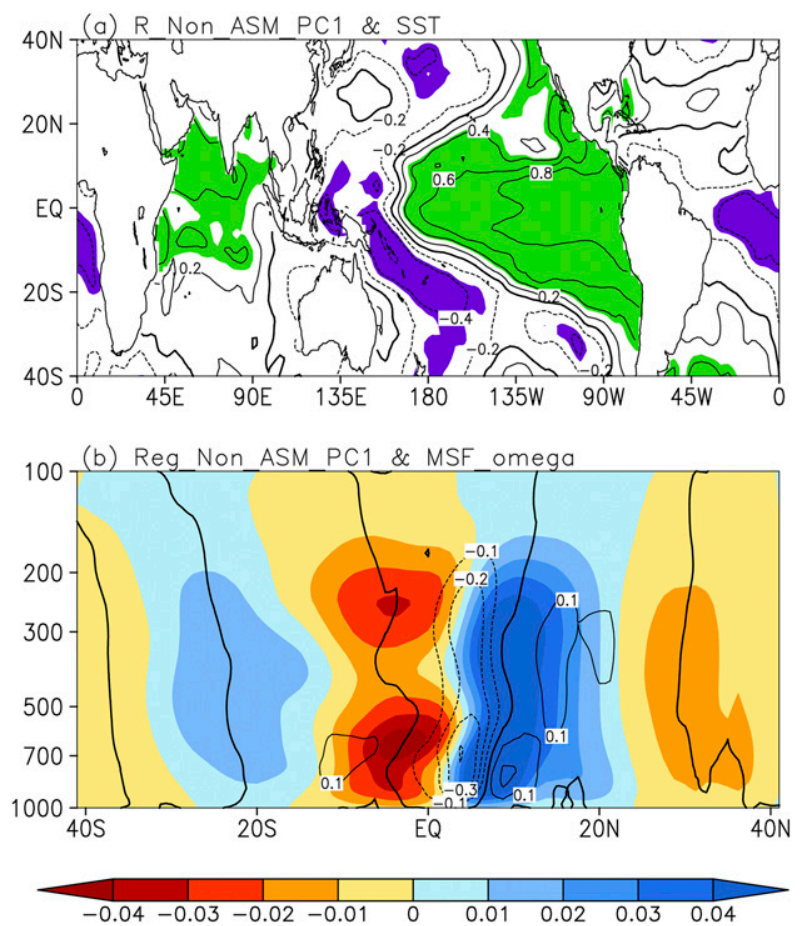

FIG. 11. (a) Correlation distribution between the SST PC1 of the non-ASM region and tropical SST. (b) Regression pattern of the MSF (shaded) and vertical motion (contours) with respect to the SST PC1 of the non-ASM region.

each hemisphere. That is, the variation of SST EOF2 in the ASM region and SST EOF1 in the non-ASM region are both responsible for the variation of the HES.

On this point, it is clear that the variation of the SST over the ASM domain contributes to the weakened ratio of the HC to different SST meridional structures during boreal summer. A homogeneous SST warming pattern dominates the variability of the SST in the ASM domain, and this warming is accompanied by an equatorially asymmetric meridional circulation. However, the direction of this anomalous circulation is opposite to the climatological HEA, suggesting that a weakened HEA would result. In contrast, the variations of the SST EOF2 in the ASM region and SST EOF1 in the non-ASM region are responsible for the HES, and neither has a significant linear trend (Figs. 13b,c). Consequently, considering the overall effects of the SST PCs, the ratio of the $\mathrm{HC}$ components to SST weakens during boreal summer.

\section{Discussion and summary}

The ratio of the $\mathrm{HC}$ responses to different SST meridional structures during the boreal summer is
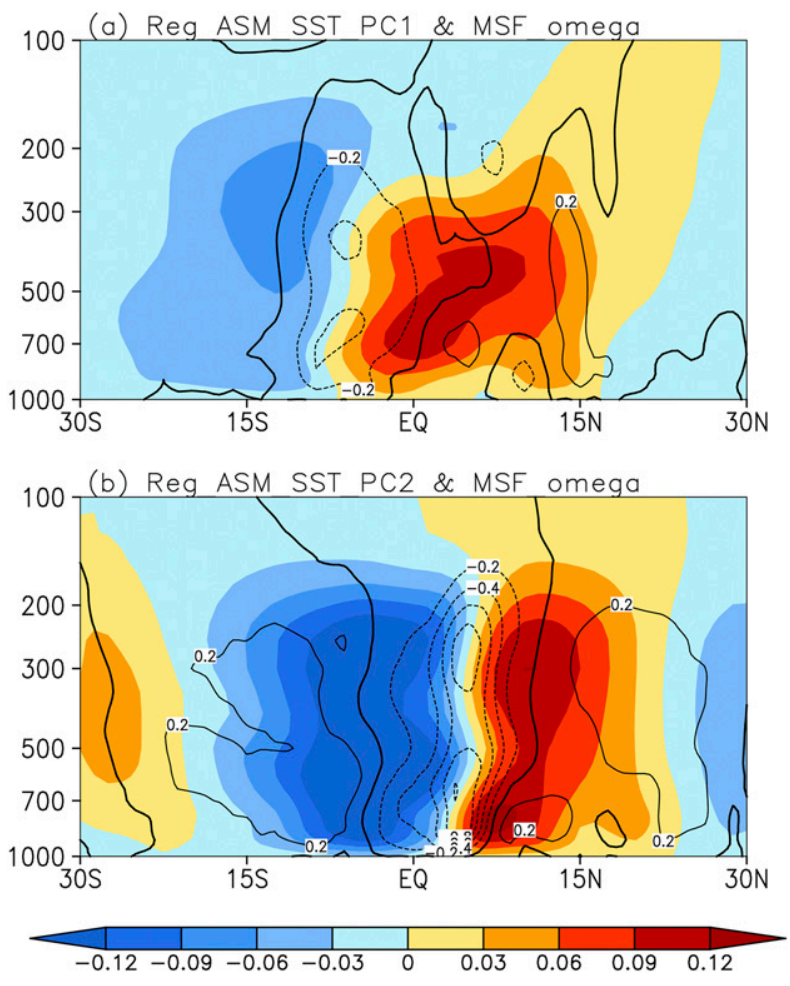

FIG. 12. (a) Regression pattern of the MSF (shaded) and vertical motion (contours) with respect to the SST PC1 of the ASM region. (b) As in (a), but for the regression with respect to the PC2.

investigated using multiple atmospheric and SST datasets. The amplitude of the HC associated with the equatorially asymmetric SST is consistently greater than that with the equatorially symmetric SST, with a ratio around 2. Note that the ratio is about 5 for the long-term annual-mean interannual variation and about 4 during the seasonal cycle. That is, the ratio of the $\mathrm{HC}$ associated with different SST meridional structures is considerably suppressed during boreal summer. Moreover, it is found that the variation of the HEA is mainly correlated with the SST in the ASM domain and with equatorially asymmetric distributed correlations in the tropical $\mathrm{Pa}$ cific and Atlantic Oceans. Accordingly, the regional HC and SST characteristics are examined further in the ASM and non-ASM regions. The variability of SST in the ASM region is dominated by two modes. The first is a homogeneous warming pattern, connected with an equatorially asymmetric $\mathrm{HC}$ that is of opposite direction to the climatological distribution of HEA. The second mode is related to an El Niño-like pattern, which mirrors the SST EOF1 in the non-ASM region. The variation of this mode is accompanied by an equatorially symmetric HC. However, only the SST EOF1 in the ASM region exhibits a significant upward trend, which 

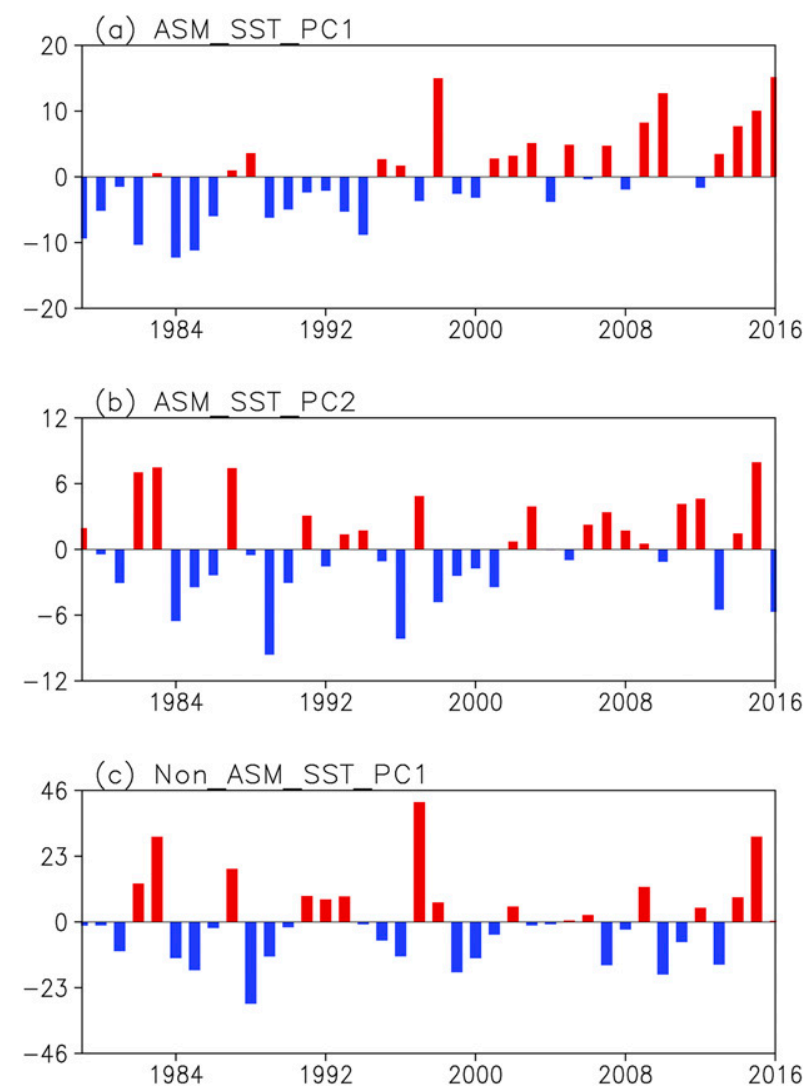

FIG. 13. (a) The SST PC1 of the ASM region. (b) As in (a), but for the PC2. (c) As in (a), but for the SST PC1 of the non-ASM region.

may weaken the variation of HEA and favors a decreased ratio of the $\mathrm{HC}$ to SST during boreal summer.

In addition, the EOF1 of the SST in the ASM domain displays a homogeneous warming pattern, and we investigate whether this mode is a reflection of global warming. We have further reexamined its variability by removing the linear trend and found that the spatial distribution of the first two modes shows little change, but with smaller explained variance (Fig. 14 vs Fig. 8). This result suggests that the SST EOF1 in the ASM region is somewhat influenced by global warming, but that other factors may be more important. Therefore, it is possible that the SST EOF1 is related to the variation of the ASM. This point is further established by the significant correlation between the SST PC1 of the ASM region and the ASM intensity index. For example, using the summer monsoon index defined by Li and Zeng (2002, 2003; available via http://ljp.gcess.cn/dct/page/1), the correlation coefficient between the SST PC1 of the ASM region and the East Asian summer monsoon index is -0.49 , and it is -0.59 using the South China Sea summer monsoon index. This suggests the hypothesis
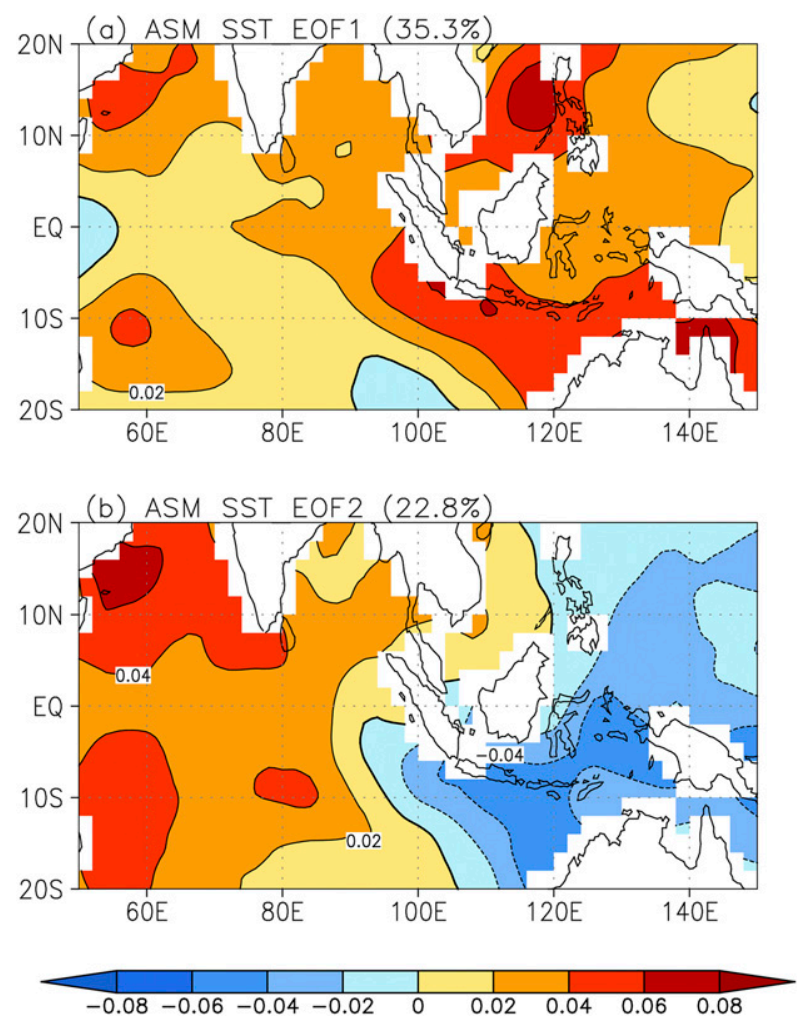

FIG. 14. Spatial distribution of the SST (a) EOF1 and (b) EOF2 of the ASM region after removing the linear trend.

that the EOF1 of SST variability in the ASM region is related to the variation of the ASM.

Moreover, it is shown that the HEA during boreal summer is mainly related to the SST in the ASM domain, which is different from the result during the equinox seasons (Feng et al. 2018). This result highlights the important modulation of the relationship between the HC and tropical SST by the ASM during boreal summer. It is known that a strong ASM is associated with negative SST anomalies within the ASM domain that facilitate a strong thermal contrast between the land and sea (e.g., Ding and Chan 2005; He et al. 2007). However, the ASM has been in a weak interdecadal phase in recent decades (He et al. 2007), favoring warm SST in the ASM domain, which in turn may play a role in affecting the ratio of the HC to SST. The modulation of the ASM on the relationship between the HC and SST is further verified based on the ERA-20C from 1948 to 2010. It is seen that the ratio of the HC to SST during boreal summer in the period of 1948-2010 is greater than that during 1979-2016 (Table 1). However, because of the limitation of the present study, the possible role of the interannual and interdecadal variation of the ASM in affecting the ratio of the HC to different SST meridional structures during boreal summer is left as an open 
question and will be discussed in our future work. Meanwhile, while the role of energy flux transports in impacting the variations of the $\mathrm{HC}$ has been explored in recent research (Trenberth and Stepaniak 2003; Lu et al. 2014; Hill et al. 2015), it is of interest to further establish the role of energy flux transports in determining the meridional structure of SST, which in turn may contribute to the variation of $\mathrm{HC}$.

On the other hand, the results in the present study provide further evidence that the associated variation of the $\mathrm{HC}$ to the equatorially asymmetric SST is more sensitive than to the symmetric SST, although with differences in the exact magnitude with different datasets. This point is consistently observed in the long-term annual mean (Feng et al. 2016), seasonal cycle (Feng et al. 2017), transition seasons (Feng et al. 2018), and in boreal summer. Meanwhile, the equatorially symmetric variation of the $\mathrm{HC}$ is mainly linked to El Niño, while the variation of the equatorially asymmetric component of the $\mathrm{HC}$ is influenced by various climatic factors. The simulation and prediction of El Niño have significantly improved in current coupled models (e.g., Jha et al. 2014; Chen et al. 2016, 2017), which will help our understanding of the equatorially symmetric variation of the HC. Therefore, it is necessary to further understand the causes of the equatorially asymmetric variation of the $\mathrm{HC}$ to facilitate a better understanding of the HC.

Finally, the relationship between the $\mathrm{HC}$ and SST during boreal summer is investigated in the present study, focusing on the interannual variation. The simultaneous relationship between the HC and SST is discussed. It is of interest to compare the result between the Atmospheric Model Intercomparison Project and Coupled Model Intercomparison Project phase simulations to further understand the potential modulation of the ASM on the linkage between the HC and SST. Furthermore, sensitivity experiments need to be carried out to understand the possible influence of the intensity of the ASM on the relationship of the HC to SST during boreal summer. In addition, this study highlights the relationship between the $\mathrm{HC}$ and different SST meridional structures, and it is expected that there may be different climatic effects of the equatorially asymmetric and symmetric variation of the HC, particularly on the regional climate. This is still an open question that will be focused on in future work.

Acknowledgments. This work was jointly supported by the SOA Program on Global Change and Air-Sea interactions (GASI-IPOVAI-03) and National Natural Science Foundation of China (41475076 and 41705131). The JRA reanalysis is available online
(http://jra.kishou.go.jp/JRA-55/index_en.html). The ERAInterim and ERA-20C reanalyses were obtained online (http://apps.ecmwf.int/datasets). The ERSST dataset was obtained from NOAA and is available online (http:// www.esrl.noaa.gov/psd/data/gridded). The HadISST dataset was obtained from the Met Office Hadley Centre and is available online (http://www.metoffice.gov.uk/hadobs/ hadisst/data/download.html).

\section{REFERENCES}

Ashok, K., S. K. Behera, S. A. Rao, H. Weng, and T. Yamagata, 2007: El Niño Modoki and its possible teleconnection. J. Geophys. Res., 112, C11007, https://doi.org/10.1029/ 2006JC003798.

Bordoni, S., and T. Schneider, 2010: Regime transitions of steady and time-dependent Hadley circulations: Comparison of axisymmetric and eddy-permitting simulations. J. Atmos. Sci., 67, 1643-1654, https://doi.org/10.1175/ 2009JAS3294.1.

Chen, L., Y. Yu, and W. Zheng, 2016: Improved ENSO simulation from climate system model FGOALS-g1.0 to FGOALS-g2. Climate Dyn., 47, 2617-2634, https://doi.org/ 10.1007/s00382-016-2988-8.

_ for the divergent projection of ENSO amplitude change under global warming. Climate Dyn., 49, 3799-3811, https://doi.org/ 10.1007/s00382-017-3544-x.

Dee, D. P., and Coauthors, 2011: The ERA-Interim reanalysis: Configuration and performance of the data assimilation system. Quart. J. Roy. Meteor. Soc., 137, 553-597, https://doi.org/ 10.1002/qj.828.

Dima, I. M., and J. M. Wallace, 2003: On the seasonality of the Hadley cell. J. Atmos. Sci., 60, 1522-1527, https://doi.org/ 10.1175/1520-0469(2003)060<1522:OTSOTH > 2.0.CO;2.

Ding, Y., and J. C. L. Chan, 2005: The East Asian summer monsoon: An overview. Meteor. Atmos. Phys., 89, 117-142, https:// doi.org/10.1007/s00703-005-0125-z.

Fang, M., and K. K. Tung, 1999: Time-dependent nonlinear Hadley circulation. J. Atmos. Sci., 56, 1797-1807, https://doi.org/10.1175/ 1520-0469(1999)056<1797:TDNHC $>2.0$. CO;2.

Feng, J., and J. Li, 2013: Contrasting impacts of two types of ENSO on the boreal spring Hadley circulation. J. Climate, 26, 47734789, https://doi.org/10.1175/JCLI-D-12-00298.1.

,,-- and F. Xie, 2013: Long-term variation of the principal mode of boreal spring Hadley circulation linked to SST over the Indo-Pacific warm pool. J. Climate, 26, 532-544, https:// doi.org/10.1175/JCLI-D-12-00066.1.

_— - — , F. Jin, Z. Liu, X. Nan, and Y. Guo, 2016: Contrasting responses of the Hadley circulation to equatorially asymmetric and symmetric meridional sea surface temperature structures. J. Climate, 29, 8949-8963, https://doi.org/10.1175/ JCLI-D-16-0171.1.

$-, \ldots, \ldots$, S. Zhao, and F. Xie, 2017: The responses of the Hadley circulation to different meridional SST structures in the seasonal cycle. J. Geophys. Res. Atmos., 122, 7785-7799, https://doi.org/10.1002/2017JD026953.

,$--\frac{1}{-}$, and F. Zheng, 2018: A comparison of the response of the Hadley circulation to different tropical SST meridional structures during the equinox seasons. J. Geophys. Res. Atmos., 123, 2591-2604, https://doi.org/10.1002/2017JD028219. 
Feng, R., J. Li, and J. Wang, 2011: Regime change of the boreal summer Hadley circulation and its connection with the tropical SST. J. Climate, 24, 3867-3877, https://doi.org/10.1175/ 2011JCLI3959.1.

Fu, Q., C. M. Johanson, J. M. Wallace, and T. Reichler, 2006: Enhanced mid-latitude tropospheric warming in satellite measurements. Science, 312, 1179, https://doi.org/10.1126/ science. 1125566.

Guo, Y.-P., and J.-P. Li, 2016: Impact of ENSO events on the interannual variability of Hadley circulation extents in boreal winter. Adv. Climate Change Res., 7, 46-53, https://doi.org/ 10.1016/j.accre.2016.05.001

- - — J. Jeng, F. Xie, C. Sun, and J. Zheng, 2016: The multidecadal variability of the asymmetric mode of the boreal autumn Hadley circulation and its link to the Atlantic multidecadal oscillation. J. Climate, 29, 5625-5641, https://doi.org/ 10.1175/JCLI-D-15-0025.1.

He, J. H., L. Qi, J. Wei, and Y. Z. Chi, 2007: Reinvestigations on the East Asian subtropical monsoon and tropical monsoon (in Chinese). Chin. J. Atmos. Sci., 31, 1257-1265.

Hill, S. A., Y. Ming, and I. M. Held, 2015: Mechanisms of forced tropical meridional energy flux change. J. Climate, 28, 17251742, https://doi.org/10.1175/JCLI-D-14-00165.1; Corrigendum, 29, 7169, https://doi.org/10.1175/JCLI-D-16-0485.1.

$\mathrm{Hu}, \mathrm{Y}$., and Q. Fu, 2007: Observed poleward expansion of the Hadley circulation since 1979. Atmos. Chem. Phys., 7, 52295236, https://doi.org/10.5194/acp-7-5229-2007.

Jha, B., Z.-Z. Hu, and A. Kumar, 2014: SST and ENSO variability and change simulated in historical experiments of CMIP5 models. Climate Dyn., 42, 2113-2124, https://doi.org/10.1007/ s00382-013-1803-z.

Kang, S. M., and J. Lu, 2012: Expansion of the Hadley cell under global warming: Winter versus summer. J. Climate, 25, 83878393, https://doi.org/10.1175/JCLI-D-12-00323.1.

Kobayashi, S., and Coauthors, 2015: The JRA-55 reanalysis: General specifications and basic characteristics. J. Meteor. Soc. Japan, 93, 5-48, https://doi.org/10.2151/ jmsj.2015-001.

Larkin, N. K., and D. E. Harrison, 2005: On the definition of El Niño and associated seasonal average U.S. weather anomalies. Geophys. Res. Lett., 32, L13705, https://doi.org/10.1029/ 2005 GL022738.

Li, J., and Q. Zeng, 2002: A unified monsoon index. Geophys. Res. Lett., 29, 1274, https://doi.org/10.1029/2001GL013874.

- and - 2003: A new monsoon index and the geographical distribution of the global monsoons. Adv. Atmos. Sci., 20, 299302, https://doi.org/10.1007/s00376-003-0016-5.

- , and J. Feng, 2017: Tropical large-scale atmospheric interaction in association with subtropical aridity trend. Aridity Trend in Northern China, C. Fu and H. Mao, Eds., Vol. 8, World Scientific Series on Asia-Pacific Weather and Climate, World Scientific Publishing, 111-136.

Li, Y., J. Li, W. Zhang, X. Zhao, F. Xie, and F. Zheng, 2015: Ocean dynamical processes associated with the tropical Pacific cold tongue mode. J. Geophys. Res. Oceans, 120, 6149-6435, https:// doi.org/10.1002/2015JC010814.

_ - — - - Q Q. Chen, J. Feng, F. Zheng, W. Wang, and X. Zhou, 2017: Impacts of the tropical Pacific cold tongue mode on ENSO diversity under global warming. J. Geophys. Res. Oceans, 122, 8524-8542, https://doi.org/10.1002/ 2017JC013052.

Lindzen, R. S., and S. Nigam, 1987: On the role of sea surface temperature gradients in forcing low-level winds and convergence in the tropics. J. Atmos. Sci., 44, 2418-2436, https:// doi.org/10.1175/1520-0469(1987)044<2418:OTROSS >2.0.CO;2.

- and A. V. Hou, 1988: Hadley circulations for zonally averaged heating centered off the equator. J. Atmos. Sci., 45, 24162427, https://doi.org/10.1175/1520-0469(1988)045<2416: HCFZAH $>2.0 . \mathrm{CO} ; 2$.

Lu, J., G. A. Vecchi, and T. Reichler, 2007: Expansion of the Hadley cell under global warming. Geophys. Res. Lett., 34, L06805, https://doi.org/10.1029/2006GL028443; Corrigendum, 34, L14808, https://doi.org/10.1029/2007GL030931.

, G. Chen, and D. M. W. Frierson, 2008: Response of the zonal mean atmospheric circulation to $\mathrm{El}$ Niño versus global warming. J. Climate, 21, 5835-5851, https://doi.org/10.1175/2008JCLI2200.1.

, C. Deser, and T. Reichler, 2009: Cause of the widening of the tropical belt since 1958. Geophys. Res. Lett., 36, L03803, https://doi.org/10.1029/2008GL036076.

- , L. Sun, Y. Wu, and G. Chen, 2014: The role of subtropical irreversible PV mixing in the zonal mean circulation response to global warming-like thermal forcing. J. Climate, 27, 22972316, https://doi.org/10.1175/JCLI-D-13-00372.1.

Ma, J., and J. Li, 2008: The principal modes of variability of the boreal winter Hadley cell. Geophys. Res. Lett., 35, L01808, https://doi.org/10.1029/2007GL031883.

Nguyen, H., A. Evans, C. Lucas, I. Smith, and B. Timbal, 2013: The Hadley circulation in reanalyses: Climatology, variability, and change. J. Climate, 26, 3357-3376, https://doi.org/10.1175/ JCLI-D-12-00224.1.

Oort, A. H., and E. M. Rasmusson, 1970: On the annual variation of the monthly mean meridional circulation. Mon. Wea. Rev., 98, 423-442, https://doi.org/10.1175/1520-0493(1970)098<0423: OTAVOT $>2.3 . \mathrm{CO} ; 2$.

, and J. J. Yienger, 1996: Observed interannual variability in the Hadley circulation and its connection to ENSO. J. Climate, 9, 2751-2767, https://doi.org/10.1175/1520-0442(1996)009<2751: OIVITH $>2.0 . \mathrm{CO} ; 2$.

Poli, P., and Coauthors, 2016: ERA-20C: An atmospheric reanalysis of the twentieth century. J. Climate, 29, 4083-4097, https://doi.org/10.1175/JCLI-D-15-0556.1.

Rayner, N. A., D. E. Parker, E. B. Horton, C. K. Folland, L. V. Alexander, D. P. Rowell, E. C. Kent, and A. Kaplan, 2003: Global analyses of sea surface temperature, sea ice, and night marine air temperature since the late nineteenth century. J. Geophys. Res., 108, 4407, https://doi.org/10.1029/ 2002JD002670.

Rind, D., and W. B. Rossow, 1984: The effects of physical processes on the Hadley circulation. J. Atmos. Sci., 41, 479-507, https:// doi.org/10.1175/1520-0469(1984)041<0479:TEOPPO>2.0.CO;2.

Schneider, E. K., and R. S. Lindzen, 1977: Axially symmetric steadystate models of the basic state for instability and climate studies. Part I: Linearized calculations. J. Atmos. Sci., 34, 263-279, https:// doi.org/10.1175/1520-0469(1977)034<0263:ASSSMO>2.0.CO;2.

Smith, T. M., R. W. Reynolds, T. C. Peterson, and J. Lawrimore, 2008: Improvements to NOAA's historical merged landocean surface temperature analysis (1880-2006). J. Climate, 21, 2283-2296, https://doi.org/10.1175/2007JCLI2100.1.

Sun, Y., and T. Zhou, 2014: How does El Niño affect the interannual variability of the boreal summer Hadley circulation? J. Climate, 27, 2622-2642, https://doi.org/10.1175/ JCLI-D-13-00277.1.

Trenberth, K. E., and D. P. Stepaniak, 2003: Seamless poleward atmospheric energy transports and implications for the Hadley circulation. J. Climate, 16, 3706-3722, https://doi.org/10.1175/ 1520-0442(2003)016<3706:SPAETA > 2.0.CO;2. 
Waliser, D. E., Z. Shi, J. R. Lanzante, and A. H. Oort, 1999: The Hadley circulation: Assessing NCEP/NCAR reanalysis and sparse in-situ estimates. Climate Dyn., 15, 719-735, https://doi. org/10.1007/s003820050312.

Walker, C. C., and T. Schneider, 2006: Eddy influences on Hadley circulations: Simulations with an idealized GCM. J. Atmos. Sci., 63, 3333-3350, https://doi.org/10.1175/JAS3821.1.

Wang, B., R. Wu, and K.-M. Lau, 2001: Interannual variability of the Asian summer monsoon: Contrasts between the Indian and western North Pacific-East Asian monsoons. J. Climate, 14, 4073-4090, https://doi.org/10.1175/1520-0442(2001)014<4073: IVOTAS $>2.0 . \mathrm{CO} ; 2$.

Wang, C., 2005: ENSO, Atlantic climate variability, and the Walker and Hadley circulations. The Hadley Circulation:
Present, Past, and Future, H. F. Diaz and R. S. Bradley, Eds., Kluwer Academic Publishers, 173-202.

— , R. H. Weisberg, and H. Yang, 1999: Effects of the wind speed-evaporation-SST feedback on the El Niño-Southern Oscillation. J. Atmos. Sci., 56, 1391-1403, https://doi.org/ 10.1175/1520-0469(1999)056<1391:EOTWSE > 2.0.CO;2.

Yu, J.-Y., and H.-Y. Kao, 2007: Decadal changes of ENSO persistence barrier in SST and ocean heat content indices: 19582001. J. Geophys. Res., 112, D13106, https://doi.org/10.1029/ 2006JD007654.

Zhang, G., and Z. Wang, 2013: Interannual variability of the Atlantic Hadley circulation in boreal summer and its impacts on tropical cyclone activity. J. Climate, 26, 8529-8544, https:// doi.org/10.1175/JCLI-D-12-00802.1. 